\title{
Prion-derived copper-binding peptide iragments catalyze the generation of superoxide anion in the presence of aromatic monoamines
}

\author{
Tomonori Kawano \\ Graduate School of Environmental Engineering, The University of Kitakyushu, Kitakyushu 808-0135, Japan
}

Correspondence to: Prof. Tomonori Kawano Graduate School of Environmental Engineering, The University of Kitakyushu, Kitakyushu 808-0135, Japan. Tel: +81-93-695-3207, Fax: +81-93-695-3304. E-mail: kawanotom@env.kitakyu-u.ac.jp

Received: 2006.08.01; Accepted: 2006.11.06; Published: 2006.11.09

Objectives: Studies have proposed two opposing roles for copper-bound forms of prion protein (PrP) as an anti-oxidant supporting the neuronal functions and as a pro-oxidant leading to neurodegenerative process involving the generation of reactive oxygen species. The aim of this study is to test the hypothesis in which putative copper-binding peptides derived from PrP function as possible catalysts for monoamine-dependent conversion of hydrogen peroxide to superoxide in vitro.

Materials and methods: Four peptides corresponding to the copper (II)-binding motifs in PrP were synthesized and used for analysis of peptide-catalyzed generation of superoxide in the presence of $\mathrm{Cu}$ (II) and other factors naturally present in the neuronal tissues.

Results: Among the Cu-binding peptides tested, the amino acid sequence corresponding to the Cu-binding site in the helical region was shown to be the most active for superoxide generation in the presence of $\mathrm{Cu}(\mathrm{II})$, hydrogen peroxide and aromatic monoamines, known precursors or intermediates of neurotransmitters. Among monoamines tested, three compounds namely phenylethylamine, tyramine and benzylamine were shown to be good substrates for superoxide-generating reactions by the $\mathrm{Cu}$-bound helical peptide.

Conclusions: Possible roles for these reactions in development of prion disease were suggested.

Key words: aromatic monoamine, copper, prion, redox, superoxide

\section{Introduction}

Prion protein $(\operatorname{PrP})$ from the brains of animals with transmissible spongiform encephalopathies (TSE) is present as partially protease-resistant form while that in uninfected brains presents as fully sensitive form [1]. In general, the former represents the infectious scrapie isoform of $\operatorname{PrP}\left(\mathrm{PrPsc}_{\mathrm{P}}\right)$ and the latter represents the intrinsic cellular $\operatorname{PrP}(\operatorname{PrPC})$. Such deposition of abnormal protein fibrils is a prominent pathological feature of many different "protein conformational" diseases, including not only "prion" dementias but also some important neurodegenerative diseases such as Alzheimer's disease, Parkinson's disease and motor neuron disease [2]. In the cases of $\beta$-amyloid which accumulates in the brain in Alzheimer's disease and of a-synuclein accumulating in Lewy bodies in Parkinson's disease, there are good evidences that the toxic mechanism involves the production of reactive oxygen species (ROS) such as $\mathrm{H}_{2} \mathrm{O}_{2}$ and hydroxyl radicals $(\mathrm{HO})$, supporting the view that one of the fundamental molecular mechanisms underlying the pathogenesis of cell death in neurodegenerative diseases could be the direct production of ROS during formation of the abnormal protein aggregates $[2,3]$.

As generalized in Fig. 1, PrPs from mammals have six to seven putative $\mathrm{Cu}$-binding sites consisted of 4 distinct sequences. Opazo et al. [4] have propounded the importance of metals in neurobiology and proposed two opposing roles for copper-bound
$\operatorname{PrP}$ as an anti-oxidant required for the neuronal functions and as a pro-oxidant leading to neurodegenerative process. To date, anti-oxidative roles of PrPC are well recognized. It has been shown that E. coli cells expressing PrP sequence (octapeptide repeats region) acquired the resistance to $\mathrm{Cu}$ and Cu-dependent oxidative damages, indicating that $\mathrm{PrPC}^{\mathrm{C}}$ possibly contributes to protection of cells from free Cu-catalyzed generation of ROS such as HO [5]. According to Wong et al. [6], Cu-bound $\mathrm{PrPC}^{\mathrm{C}}$ shows a superoxide dismutase (SOD)-like activity in vitro, and its expression likely contributes to the cellular response to oxidative damages to the cells. Sauer et al. [7] have shown in tumor spheroids that an increase in ROS stimulates the production of $\mathrm{PrPC}$ and other ROS scavenging enzymes such as $\mathrm{Cu}, \mathrm{Zn}-\mathrm{SOD}$ and catalase, while ROS-lowering treatments effectively down-regulate the expression of $\mathrm{PrPC}$, implying that $\mathrm{PrPC}$ expression in tumor spheroids is regulated by the internal redox state to meet the requirement to protect the cells from ROS. Interestingly, a drastic depress in SOD-like activity has been shown in the affinity-purified total $\mathrm{PrP}$ preparation isolated from scrapie-infected mouse brains suggesting that prion disease results in denature of PrP thus no longer active in ROS removal [6].

However, contrary to above reports, there are views questioning the proposed SOD-like activity of PrPs. Jones et al. [8] have reported that recombinant PrP exhibits no detectable dismutase activity above baseline levels measured for copper (II) ions. 
It is generally accepted that, like amyloid- $\beta$ peptide, prion induces apoptotic cell death in neuronal tissues [9]. A PrP amino acid sequence 106-126 covering a putative Cu-binding site, likely forms the region causing neuronal apoptosis since a synthetic Cu-bound peptide corresponding to $\operatorname{PrP}$ 106-126 is highly fibrillogenic and highly toxic to neuronal cells as if behaving as a PrPsc mimic $[9,10]$.

Figure 1. Copper-binding motifs in PrP protein. (A) Putative copper-binding domains present in PrP protein and variations in amino acid sequences required for binding to copper. Histidine residues possibly involved in anchoring of copper are marked with asterisks. (B) Four peptide sequences corresponding to copper-binding motifs in PrP. (1) The most characterized $\mathrm{Cu}$-binding sequence repeated 4 times in human, mouse and ovine, 6 times in bovine was used. (2) An additional $\mathrm{Cu}$ binding sequence found in the basic region in human and mouse PrPs immediately after the octarepeats. (3) PrPs from mammals and chicken show similar sequences, but human sequence was tested. (4) Well characterized analog for PrP helix 2 sequence was used [33]. The PrP helix 2 sequences varied among species but the $\mathrm{Cu}$-anchoring $\mathrm{H}$ residue is highly conserved in various mammals such as mouse, bovine, ovine, tammar wallaby, brush-tailed possum, and Brazilian opossum.

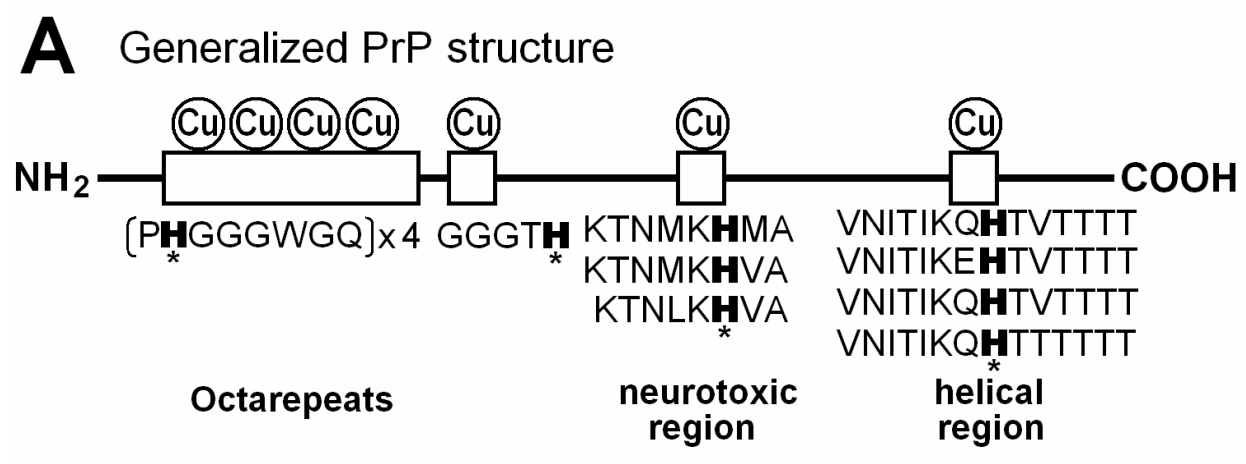

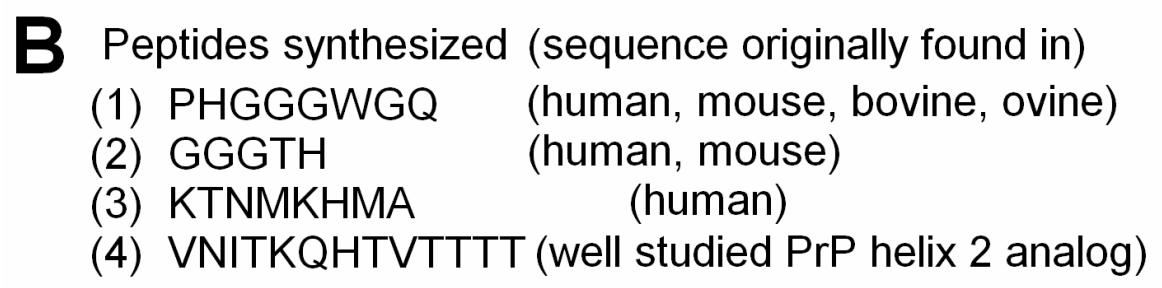

Through in vitro studies with electron spin resonance spectroscopy, Allsop and his colleagues have shown that $\mathrm{H}_{2} \mathrm{O}_{2}$ (detected with a spin trap after conversion to $\mathrm{HO}$ via Fenton reaction) is produced during the early stages of protein aggregation associated with neurodegenerative diseases involving $\beta$-amyloid, a-synuclein and toxic forms of $\operatorname{PrP}$ [11-13]. Especially Cu-loaded $\operatorname{PrP} 106-126$, the neurotoxic region, likely catalyzes the robust generation of $\mathrm{H}_{2} \mathrm{O}_{2}$ [12].

In addition to the Cu-loaded PrP peptide-dependent formation of $\mathrm{H}_{2} \mathrm{O}_{2}$, the present study reports the production of superoxide anion $\left(\mathrm{O}_{2}{ }^{-}\right)$, another key member of ROS in biological systems, by Cu-binding PrP fragments in the presence of certain co-factors. Previously, the author has proposed a hypothetical model mechanism in which $\mathrm{Cu}$-bound form of PrP catalyzes the generation of ROS in the presence of some natural co-factors at specific occasions in the neuronal tissues [14]. The author has made a speculation that aromatic monoamines may form a group of such co-factors possibly contributing to the PrP-dependent oxidative burst [14] since Cu-bound PrP has high affinity and catalytic activity for oxidation of some aromatic monoamines such as dopamine which is abundantly present in neuronal tissues [15]. The aim of the present study is to test the hypothesis in which putative $\mathrm{Cu}$-binding peptides derived from PrP function as possible catalysts for monoamine-dependent conversion of $\mathrm{H}_{2} \mathrm{O}_{2}$ to $\mathrm{O}_{2}$ - in vitro.

\section{Materials and methods}

\section{Peptides}

Four peptides corresponding to each Cu-binding sequence in PrP protein were synthesized to examine the behavior of such Cu-binding domains in chemiluminescence analysis of peptide-mediated oxidative burst. The peptides were obtained from the custom peptide service department of Sigma Genosis Japan (Ishikari, Hokkaido). The amino acid sequences of the peptides chemically synthesized and purified on high pressure liquid chromatography were (1) PHGGGWGQ (purity, 95.72\%), (2) GGGTH (purity, $98.98 \%$ ), (3) KTNMKHMA (purity, 98.85\%) and (4) VNITKQHTVTTTT (purity, 99.02\%).

\section{Chemicals}

2-Methyl-6-phenyl-3,7-dihydroimidazo[1,2-a]py razin-3-one (Cypridina luciferin analog, CLA), a chemiluminescence reagent specific to $\mathrm{O}_{2}{ }^{\circ}$, was purchased from Tokyo Kasei Kogyo Co. (Tokyo, Japan). Phenylethylamine (PEA), tyramine hydrochloride, and tryptamine hydrochloride were purchased from Wako Pure Chemical Industries Ltd. (Osaka, Japan). Benzylamine, dopamine hydrochloride, and serotonin were from Nakalai Tesque Inc. (Kyoto, Japan). Other chemicals used in this study were of reagent grade purchased from Sigma (St. Louis, MO, USA). 


\section{Detection of superoxide}

The peptides and other chemicals were dissolved in phosphate buffered saline and generation of $\mathrm{O}_{2}{ }^{-}$ was monitored by chemiluminescence of CLA with a CHEM-GLOW Photometer (American Instrument Co., MD., USA) equipped with a pen recorder, and expressed as relative luminescence units (rlu) as previously described [16]. CLA-chemiluminescence specifically indicates the generation of $\mathrm{O}_{2}{ }^{\cdot-}$ (and ${ }^{1} \mathrm{O}_{2}$ with a lesser extent) but not that of $\mathrm{O}_{3}, \mathrm{H}_{2} \mathrm{O}_{2}$ or $\mathrm{HO}^{*}$ [17]. According to our previous study, the signal for ${ }^{1} \mathrm{O}_{2}$ can be minimized by avoiding the use of high concentration of organic solvents such as ethanol over $2 \%(\mathrm{v} / \mathrm{v})$ in the culture media [18]. Thus the induced chemiluminescence recorded here reflects the generation of $\mathrm{O}_{2}{ }^{-}$- rather than ${ }^{1} \mathrm{O}_{2}$.

\section{Results}

\section{Aromatic monoamine-dependent oxidative burst catalyzed by the helical $\mathrm{Cu}$-bound peptide}

Since earlier studies suggested the high affinity of PrP towards dopamine and related monoamines [15], direct interactions between PrP-derived peptides and some aromatic monoamines leading to generation of $\mathrm{O}_{2}{ }^{-}$- was examined in phosphate buffered saline containing $5 \mu \mathrm{M}$ CLA, by measuring the $\mathrm{O}_{2}{ }^{\bullet-}$-specific chemiluminescence. However, we observed no increase in $\mathrm{O}_{2}{ }^{-}$-dependent chemiluminescence in the reaction mixture simply consisted of peptides and aromatic monoamines (data not shown). Then, addition of other co-factors such as $\mathrm{CuSO}_{4}$ and $\mathrm{H}_{2} \mathrm{O}_{2}$ were examined by analogy to the catecholamine-dependent oxidative burst-catalyzing enzymes such as copper-amine oxidases, monoamine oxidases and monoamine-oxidizing peroxidases. Here, generation of $\mathrm{O}_{2}{ }^{--}$was examined by adding CLA, peptide, $\mathrm{Cu}, \mathrm{H}_{2} \mathrm{O}_{2}$ and aromatic monoamines to phosphate buffered saline in this order. In the reaction mixture $(200 \mu \mathrm{l})$ containing helical peptide (VNITKQHTVTTTT), $\mathrm{Cu}^{2+}, \quad \mathrm{H}_{2} \mathrm{O}_{2}, \quad$ and phenylethylamine (PEA) with an approximate molar ratio of $1: 3: 3: 10$, a robust increase in the $\mathrm{O}_{2}{ }^{\bullet-}$-dependent chemiluminescence was observed (Fig. 2A). The observed burst of $\mathrm{O}_{2}{ }^{-}$production was a biphasic event consisting of the acute spike and the gradual increase in $\mathrm{O}_{2}{ }^{\circ}$. As discussed below, the PEA-induced acute spike can be observed in the $\mathrm{Cu}-\mathrm{H}_{2} \mathrm{O}_{2}$ solution lacking peptides, only the later phase with gradual large increase in chemiluminescence must be attributed to the helical peptide-dependent reactions. Other peptides except for GGGTH also showed catalytic activity leading to biphasic $\mathrm{O}_{2}{ }^{\bullet-}$ production with lesser extents. Here again, only the secondary phase of oxidative burst must be considered as the consequences of peptide chemistry. Among the peptides, the activity of VNITKQHTVTTTT peptide sequence was outstanding thus is of great interests.

The cases of tyramine instead of PEA added to the reaction mixture containing $5 \mu \mathrm{M}$ CLA, $0.3 \mu \mathrm{M}$ helical peptide, $0.9 \mu \mathrm{M} \mathrm{CuSO}_{4}$, and $1 \mathrm{mM} \mathrm{H}_{2} \mathrm{O}_{2}$ are shown in Fig. 2B. Effects of various aromatic amines namely PEA, tyramine, dopamine, serotonin, tryptamine, benzylamine, on generation of $\mathrm{O}_{2} \cdot-$ in peptide- $\mathrm{Cu}-\mathrm{H}_{2} \mathrm{O}_{2}$ system were compared (Fig. 2B, upper inset). Among the aromatic monoamines, only three monoamines, PEA, tyramine, and benzylamine induced the generation of $\mathrm{O}_{2}{ }^{\bullet}$, and the structures of such active monoamines are shown in Fig. 2C. In addition, effects of two salicylates known to stimulate the conversion of $\mathrm{H}_{2} \mathrm{O}_{2}$ to $\mathrm{O}_{2}{ }^{-}$by human methemoglobin $[19,20]$ and various peroxidases [20], were also tested (Fig. 2B, upper inset). However, these salicylates were shown to be poor substrates for the generation of $\mathrm{O}_{2}{ }^{-}$in this system. Interestingly, five related compounds inactive in induction of $\mathrm{O}_{2}{ }^{-}$ namely, serotonin, tryptamine, dopamine, salicylate and aspirin were shown to interfere with the PEA-induced $\mathrm{O}_{2}{ }^{\circ-}$-generating reaction (Fig. 2B, lower inset), opening the ways for chemical and clinical modulation or manipulation of the monoamine-dependent oxidative burst in the PrP rich neuronal tissues.

As the helical peptide was shown to be most active among four $\mathrm{Cu}$-binding peptides derived from $\mathrm{PrP}$ as the catalyst for PEA-dependent generation of $\mathrm{O}_{2}{ }^{\circ}$, three other peptides less active towards PEA were shown to be also poorly active even towards tyramine and benzylamine (data not shown).

Among, three active monoamines, PEA is the most abundant species in neuronal tissues since PEA is a key precursor for many of catecholamine neurotransmitters. It is likely that reaction involving PEA is most likely to occur in the neuronal tissues compared to the reactions involving tyramine or benzylamine, thus following assays were carried out using PEA as a possible substrate.

\section{Requirement for co-factors}

In the reaction mixtures lacking either of 5 components namely CLA, helical peptide, $\mathrm{Cu}, \mathrm{H}_{2} \mathrm{O}_{2}$ and aromatic monoamines, no drastic increase in the second phase of $\mathrm{O}_{2}{ }^{-}$-dependent chemiluminescence was observed, suggesting that any component is necessarily required for the reaction leading to generation and detection of $\mathrm{O}_{2}{ }^{\bullet}$ - Typical results for peptide- $\mathrm{Cu}-\mathrm{H}_{2} \mathrm{O}_{2}-\mathrm{PEA}$ system are shown (Fig. 3). Effects of the concentrations of helical peptide (Fig. 3A), copper (Fig. 3B), $\mathrm{H}_{2} \mathrm{O}_{2}$ (Fig. 3C), and PEA (Fig. 3D) on $\mathrm{O}_{2}{ }^{\circ-}$ generation were examined. All components of the reaction were shown to act in concentration-dependent manners, further confirming that each component is necessary for the $\mathrm{O}_{2}{ }^{\circ}$ generating reaction and thus each component can be a limiting factor. Since the requirement for $\mathrm{H}_{2} \mathrm{O}_{2}$ was confirmed, the type of reaction catalyzed by the Cu-supplemented PrP helical sequence is rather similar to the aromatic monoamine oxidation reactions leading to $\mathrm{O}_{2}{ }^{\bullet-}$ generation catalyzed by $\mathrm{H}_{2} \mathrm{O}_{2}$-requiring plant peroxidases [21, 22] or human methemoglobin [19].

Here, the $\mathrm{Cu}$-loaded peptide-dependent $\mathrm{O}_{2}{ }^{-}$ generation was shown to be fueled by $\mathrm{H}_{2} \mathrm{O}_{2}$ added to the reaction mixture. Actually, supply of $\mathrm{H}_{2} \mathrm{O}_{2}$ at the micro-domains on $\mathrm{Cu}$-bound whole $\mathrm{PrP}$ is possible since Cu-loaded PrP 106-126, the neurotoxic region, is known to catalyze the production of $\mathrm{H}_{2} \mathrm{O}_{2}$ [12]. Despite of weak $\mathrm{O}_{2}{ }^{\circ}$-generating activity of KTNMKHMA corresponding to the neurotoxic sequence (Fig. 2A), this region may contribute to the oxidative burst by producing $\mathrm{H}_{2} \mathrm{O}_{2}$. 
Figure 2. Superoxide-generating reactions catalyzed by the $\mathrm{Cu}$-supplied $\mathrm{PrP}$ peptide fragments. (A) Typical traces of $\mathrm{O}_{2}{ }^{\circ}$-dependent chemiluminescence increase catalyzed by four putative $\mathrm{Cu}$-binding PrP fragments are shown. Each reaction mixture contained CLA $(5 \mu \mathrm{M})$, either peptide sequence as indicated $\left(0.3 \mathrm{mM}\right.$ each), $\mathrm{CuSO}_{4}(0.9 \mathrm{mM}), \mathrm{H}_{2} \mathrm{O}_{2}(1 \mathrm{mM})$ and PEA ( $3 \mathrm{mM})$. (B) Comparison of the actions of aromatic monoamines. Reaction mixtures contained $5 \mu \mathrm{M}$ CLA, $0.3 \mathrm{mM}$ helical peptide, $0.9 \mathrm{mM} \mathrm{CuSO}, 1 \mathrm{mM} \mathrm{H}_{2} \mathrm{O}_{2}$, and $3 \mathrm{mM}$ of aromatic monoamies or salicylates. Typical traces for tyramine-induced oxidative burst with and without helical peptide are shown. The $\mathrm{O}_{2}{ }^{\circ-}$-generating activities of related compounds were compared in upper inset. Asterisk, $\mathrm{O}_{2}{ }^{-}$can be observed in serotonin-Cu solution lacking the peptide suggesting that observed chemilumienscence is not reflecting the peptide dependent generation of $\mathrm{O}_{2}{ }^{\circ}$. The lower inset shows that five compounds shown to be inactive in oxidative burst induction, in turn inhibits the PEA-dependent $\mathrm{O}_{2}{ }^{\circ}$ generation. Prior to addition of PEA to the reaction mixture, each inhibitory compound ( $3 \mathrm{mM})$ was added. (C) Structures of aromatic monoamines active in $\mathrm{Cu}$-loaded $\mathrm{PrP}$ helical peptide-dependent production of $\mathrm{O}_{2}{ }^{\circ}$. (1) Phenylethylamine (PEA), (2) tyramine, (3) benzylamine.
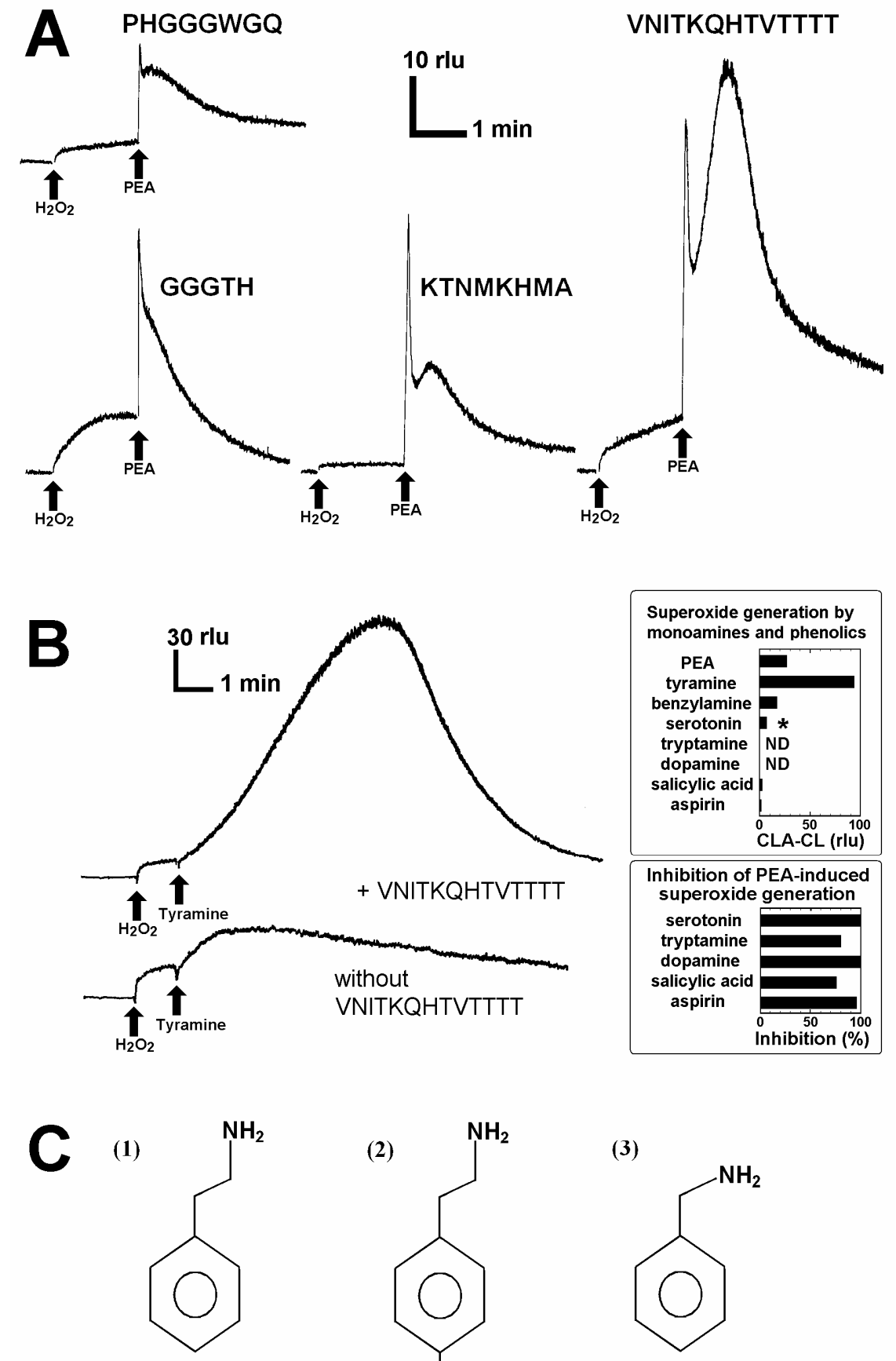<smiles>NCCc1ccc(O)cc1</smiles>

(3)<smiles>NCc1ccccc1</smiles> 
Figure 3. Effects of the concentrations of peptide-, copper-, $\mathrm{H}_{2} \mathrm{O}_{2-}$, and PEA on superoxide generation. (A) Effect of the helical peptide concentration. (B) Effect of $\mathrm{CuSO}_{4}$ concentration. (C) Effect of $\mathrm{H}_{2} \mathrm{O}_{2}$ concentration. (D) Effect of PEA concentration. Basically, the reaction mixtures contained constant amounts of CLA $(5 \mu \mathrm{M})$, the helical peptide sequence $(0.3$ $\mathrm{mM}$, exception in $\mathrm{A}), \mathrm{CuSO}_{4}(0.9 \mathrm{mM}$, exception in $\mathrm{B}), \mathrm{H}_{2} \mathrm{O}_{2}(1 \mathrm{mM}$, exception in $\mathrm{C})$ and PEA (3 mM, exception in D).
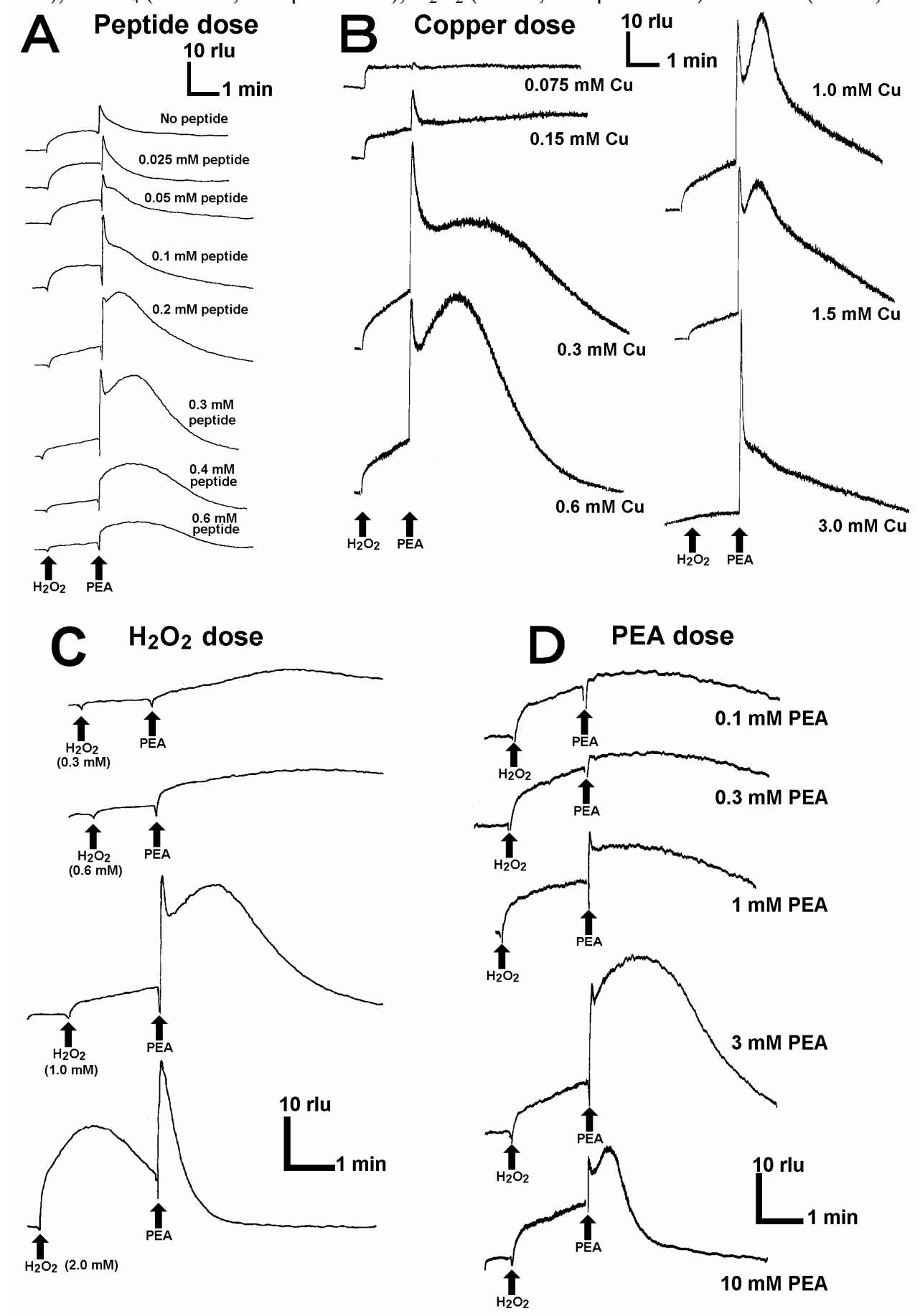

\section{Discussion}

\section{Cu-binding sites on PrP}

Importance of metalloproteins in neurobiology has been shown both as oxidant and antioxidant in neurodegenerative processes [4]. $\mathrm{Cu}$ is an essential trace element but its redox reactivity leads to the risk of damage to the cells and tissues, especially in neurodegenerative diseases such as Menkes' and Wilson's diseases occurring via disorders of $\mathrm{Cu}$ metabolism, and Alzheimer's disease and 'prion' diseases, the two major conformational diseases, as documented [23-25, etc]. The likely roles for $\mathrm{Cu}$ in

induction of critical steps in the apoptotic pathways leading to neurodegeneration is outlined in the above reviews.

Recent studies have shown that PrPs can form a novel group of $\mathrm{Cu}$-binding proteins [26,27]. Human PrP has four Cu-binding sites in the "octarepeats" region (PrP 60-91) in which amino acid sequence PHGGGWGQ appears four times and each repeat possibly binds single $\mathrm{Cu}^{2+}$ at physiological neutral and basic range of $\mathrm{pH}$ [28]. In general, the most relevant copper binding mode would involve formation of a 4:1 octarepeat: $\mathrm{Cu}$ complex involving coordination of one single $\mathrm{Cu}$ molecule by the 4 
histidines on the 4 octarepeat segments of a single $\mathrm{PrP}$ molecule [29]. In chicken, the Cu-binding sites analogous to the octarepeats are known as hexa-repeats with each repeat consisting of the amino acid sequence HNPGYP and here again His residues play a key role in anchoring of $\mathrm{Cu}$ [30]. Morante et al. [31] showed that partial occupancy of $\mathrm{Cu}$ on bovine $\mathrm{PrP}$ is manifested by binding of $\mathrm{Cu}$ to $\mathrm{PrP}$ in the intermolecular or inter-octarepeat orientations while total occupancy of $\mathrm{Cu}$ is manifested by intra-repeat binding of $\mathrm{Cu}$ to the octarepeat region.

In vitro studies have shown that the actual least motif in the octarepeats necessarily required for binding of $\mathrm{Cu}$ consists of 4 amino acids HGGG [28] or 5 amino acids HGGGW [32]. Although there are additional Cu-binding sites on $\mathrm{PrP}$ such as amino acid regions 92-96 (GGGTH) [27], 124-126 (KHM) [10] and 180-193 (VNITIKQHTVTTTT) [33], and all studies suggested that His residue in each region (or each repeat unit) plays a key role in anchoring of $\mathrm{Cu}$ (Fig. 1) Based on above knowledge, four peptides corresponding to $\mathrm{Cu}$-binding domains on PrP, namely PHGGGWGQ (repeated in PrP 60-91), GGGTH (PrP 92-96), KTNMKHMA (PrP 120-127) and VNITKQHTVTTTT (helical, PrP 180-193 analog) were synthesized in the present study and the helical Cu-binding motif was shown to be the most active in monoamine-dependent generation of $\mathrm{O}_{2}{ }^{-*}$. Although the octarepeat-dependent oxidative burst (second phase) was about one forth of the helical peptide-dependent one, this amino acid octet is repeated 4 times in human PrP and 6 times in bovine $\operatorname{PrP}$, its contribution to oxidative burst in whole protein can be greater than that observed for the single repeat peptide.

\section{Redox regulations}

The amino-terminal part of $\operatorname{PrP}(23-98)$ is rich in amino acid residues susceptible to oxidation, such as His, Lys, Arg, and Pro, thus PrP is sensitive to oxidative changes such as production of ROS and the conformational changes in $\operatorname{PrP}$ may be readily induced by redox changes $[15,34]$. In addition to the above amino acid residues on $\mathrm{PrP}$, Met residues may be good targets for attacks by ROS. Recently, $\mathrm{H}_{2} \mathrm{O}_{2}$-dependent oxidation of Met residues has been reported for recombinant Syrian hamster PrP (29-231) [35]. The likely target residues include $\operatorname{Met}^{109}$, $\operatorname{Met}^{112}$, $\operatorname{Met}^{129}$ and Met $^{134}$ and the susceptibility to oxidation of each Met residue was shown to be a function of accessibility to the solvent. While $\mathrm{Cu}$-catalyzed oxidation leads to extensive aggregation of PrP, the $\mathrm{H}_{2} \mathrm{O}_{2}$-dependent Met oxidation on PrP leads only to a modest increase in $\beta$-sheet structure.

According to recently proposed model, there may be an intermediate structure of $\mathrm{PrP}$ between $\mathrm{PrPC}$ and $\mathrm{PrPSc}$, to be formed from $\mathrm{PrPC}$ in response to cellular redox changes thus designated as PrPRDX [36]. An in vitro study demonstrated that PrPRDX of recombinant hamster $\mathrm{PrP}$ is catalytically active and capable of further conversion of PrPC to PrPRDX. At the end, $\operatorname{PrPRDX}$ accumulates and disulfide bonds are formed among each PrPRDX molecule, and lastly formation of PrPSc is completed. This attractive model successfully explained how pathogenic form of PrP could be propagated by the presence of an intermediate PrP.

Note that the PrPRDX originally proposed by Lee and Eisenberg [36] was described to be in the oligomeric form distinct from the inert $\mathrm{SH}$ swapped dimeric form. Due to the nature of experimental design aimed to produce the redox-activated $\operatorname{PrP}$ oligomers at once from the SH-opened PrP monomers produced by exposing the bulk of $\operatorname{PrP}$ to the stepwise reduction and oxidation, their model (domain-swapping model) lacks the idea on the very initial event possibly occurring on a single molecule. Here the author wish to mention that PrP-catalyzed generation of $\mathrm{O}_{2} \cdot$ - (that may attack the $\mathrm{SH}$ residues on $\operatorname{PrP})$ as a possible redox step(s) that converts the monomeric native $\mathrm{PrPC}^{\mathrm{C}}$ to the catalytically active monomeric PrPRDX intermediate which in turn acts as the seed for further production of PrPRDX from PrPC, and to elongate the oligomers. The latest report by Shiraishi et al. [37] supports the view that the $\mathrm{Cu}$ bound to $\operatorname{PrP}$ undergoes catalytic cycling in the presence of catecholamines and causes the oxidation of protein, possibly involving the ROS-generating reactions which is sensitive to copper chelators, catalase and also to SOD, implying the involvements of $\mathrm{H}_{2} \mathrm{O}_{2}$ and $\mathrm{O}_{2}{ }^{\circ}$. Possible contribution of PrP-catalyzed redox changes such as oxidation of catecholamines accompanying productions of $\mathrm{H}_{2} \mathrm{O}_{2}$ and $\mathrm{O}_{2}{ }^{-*}$, in aid of $\operatorname{PrPRDX}$ generation is worth of further examination.

\section{Abbreviations}

CLA: Cypridina luciferin analog; $\mathrm{HO}$ : hydroxyl radicals; MAO: monoamine oxidase; $\mathrm{O}_{2} \bullet$ : superoxide anion; PEA: phenylethylamine; PrP: prion protein; PrPC: intrinsic cellular PrP; PrPSc: scrapie isoform of PrP; PrPRDX: PrP redox intermediate; rlu: relative luminescence units; ROS: reactive oxygen species; SOD: superoxide dismutase; TSE: transmissible spongiform encephalopathies.

\section{Conflict of interest}

\section{Declared none.}

\section{References}

1. Jeffray M, McGovern G, Goodsir CM, et al. Sites of prion protein accumulation in scrapie-infected mouse spleen revealed by immuno-electron microscopy. J Pathol 2000; 191: 323-32.

2. Tabner BJ, Turnbull S, El-Agnaf O, et al. Production of reactive oxygen species from aggregating proteins implicated in Alzheimer's disease, Parkinson's disease and other neurodegenerative diseases. Curr Top Med Chem 2001; 1: 507-17.

3. Tabner BJ, El-Agnaf OMA, Turnbull S, et al. Hydrogen peroxide is generated during the very early stages of aggregation of the amyloid peptides implicated in Alzheimer's disease and familial British dementia. J Biol Chem 2005; 280: 35789-92.

4. Opazo C, Barria MI, Ruiz FH, et al. Copper reduction by copper binding proteins and its relation to neurodegenerative diseases. Biometals 2003; 16: 91-8.

5. Shiraishi N, Ohta $Y$, and Nishikimi M. The octapeptide repeat region of prion protein binds $\mathrm{Cu}(\mathrm{II})$ in the redox inactive states. Biochem Biophys Res Commun 2000; 267: 398-402.

6. Wong BS, Brown DR, Pan T, et al. Oxidative impairment in scrapie-infected mice is associated with brain metals perturbations and altered antioxidant activities. J Neurochem 2001; 79: 689-98.

7. Sauer H, Dagdanova A, Hescheler J, et al. Redox-regulation of intrinsic prion expression in multicellular prostate tumor spheroids. Free Radic Biol Med 1999; 27: 1276-83. 
8. Jones $\mathrm{S}$, Batchelor $\mathrm{M}$, Bhelt $\mathrm{D}$, et al. Recombinant prion protein does not possess SOD-1 activity. Biochem J 2005; 392: 309-12.

9. Agostinho P, Oliveira CR. Involvement of calcineurin in the neurotoxic effects induced by amyloid- $\beta$ and prion peptides. Eur J Neurosci. 2003; 17: 1189-96.

10. Belosi B, Gaggelli E, Guerrini R, et al. Copper binding to the neurotoxic peptide PrP106-126: thermodynamic and structural studies. Chembiochem 2004; 5: 349-59.

11. Tabner BJ, Turnbull S, Fullwood NJ, et al. The production of hydrogen peroxide during early-stage protein aggregation: a common pathological mechanism in different neurodegenerative diseases? Biochem Soc Trans 2005; 33: 548-50.

12. Turnbull S, Tabner BJ, Brown DR, et al. Copper-dependent generation of hydrogen peroxide from the toxic prion protein fragment PrP106-126. Neurosci Lett 2003; 336: 159-62.

13. Turnbull S, Tabner BJ, Brown DR, et al. Generation of hydrogen peroxide from mutant forms of the prion protein fragment PrP 121-231. Biochemistry 2003; 42: 7675-81.

14. Furuichi T, and Kawano T. Possible application of electron spin resonance to monitoring of prion diseases and hypotheses on oxidative action and propagation of copper-bound infectious protein. Bull Nippon Sport Sci Univ 2005; 35: 71-80.

15. Shiraishi N, and Nishikimi M. Carbonyl formation on a copper-bound prion protein fragment, PrP23-98, associated with its dopamine oxidase activity. FEBS Lett 2002; 511: 118-22.

16. Kawano T, Kawano N, Hosoya H, et al. Fungal auxin antagonist hypaphorine competitively inhibits indole-3-acetic acid-dependent superoxide generation by horseradish peroxidase. Biochem Biophys Res Commun 2001; 288: 546-51.

17. Nakano M, Sugioka K, Ushijima Y, et al. Chemiluminescence probe with Cypridina luciferin analog, 2-methyl-6-phenyl-3,7-dihydroimidazo[1,2-a]pyrazin-3-one, for estimating the ability of human granulocytes to generate $\mathrm{O}_{2}$ Anal Biochem 1986; 159: 363-9.

18. Yokawa K, Suzuki N, and Kawano T. Ethanol-enhanced singlet oxygen-dependent chemiluminescence interferes with the monitoring of biochemical superoxide generation with a chemiluminescence probe, Cypridina luciferin analog. ITE Lett Batter New Technol Medic 2004; 5: 49-52.

19. Kawano T, Pinontoan R, Hosoya $\mathrm{H}$, et al. Monoamine-dependent production of reactive oxygen species catalyzed by pseudoperoxidase activity of human hemoglobin. Biosci Biotechnol Biochem 2002; 66: 1224-32.

20. Kawano T. Roles of the reactive oxygen species-generating peroxidase reactions in plant defense and growth induction. Plant Cell Rep 2003; 2: 829-37.

21. Kawano T, Pinontoan R, Uozumi N, et al. Aromatic monoamine-induced immediate oxidative burst leading to an increase in cytosolic $\mathrm{Ca}^{2+}$ concentration in tobacco suspension culture. Plant Cell Physiol 2000; 41: 1251-8.

22. Kawano T, Pinontoan R, Uozumi N, et al.
Phenylethylamine-induced generation of reactive oxygen species and ascorbate free radicals in tobacco suspension culture: mechanism for oxidative burst mediating $\mathrm{Ca}^{2+}$ influx. Plant Cell Physiol 2000; 41: 1259-66.

23. Rossi L, Lombardo MF, Ciriolo MR, et al. Mitochondrial dysfunction in neurodegenerative diseases associated with copper imbalance. Neurochem Res 2004; 29: 493-504.

24. Vassallo N, and Herms J. Cellular prion protein function in copper homeostasis and redox signaling at the synapse. J Neurochem 2003; 86: 538-44.

25. Rotilio G, Carri MT, Rossi L, et al. Copper-dependent oxidative stress and neurodegeneration. IUBMB Life 2000; 50: 309-14.

26. Aronoff-Spencer E, Burns CS, Avdievich NI, et al. Identification of the $\mathrm{Cu}^{2+}$ binding sites in the N-terminal domain of the prion protein by EPR and CD spectroscopy. Biochemistry 2000; 39: 13760-71.

27. Burns CS, Aronoff-Spencer E, Legname G, et al. Copper coordination in the full-length, recombinant prion protein. Biochemistry 2003; 42: 6794-803.

28. Bonomo RP, Imperllizzeri G, Pappalardo G, et al. Copper II binding modes in the prion octapeptide PHGGWGGQ: a spectroscopic and voltammetric study. Chemistry 2000; 6: 4195-202.

29. Wells MA, Jelinska C, Hosszu LL, et al. Multiple forms of copper (II) coordination occur throughout the disordered $\mathrm{N}$-terminal region of the prion protein at $\mathrm{pH}$ 7.4. Biochem J 2006; [Epub ahead of print]

30. Stanczak P, Luczkowski M, Juszczyk P, et al. Interactions of $\mathrm{Cu}^{2+}$ ions with chicken prion tandem repeats. Dalton Trans 2004; 14: 2102-7.

31. Morante S, Gonzalez-Iglesias R, Potrich C, et al. Inter- and intra-octarepeat $\mathrm{Cu}(\mathrm{II})$ sites geometries in the prion protein. J Biol Chem 2004; 279: 11753-9.

32. Burns CS, Aronoff-Spencer E, Dunham CM, et al. Molecular features of the copper binding sites in the octarepeat domain of the prion protein. Biochemistry 2002; 41: 3991-4001.

33. Brown DR, Guantieri V, Grasso G, et al. Copper(II) complexes of peptide fragments of the prion protein. Conformation changes induced by copper(II) and the binding motif in C-terminal protein region. J Inorg Biochem 2004; 98: 133-43.

34. Requena JR, Groth D, Legname G, et al. Copper-catalyzed oxidation of the recombinant $\mathrm{SHa}(29-231)$ prion protein. Proc Natl Acad Sci USA 2001; 98: 7170-5.

35. Requena JR, Dimitrova MN, Legname D, et al. Oxidation of methionine residues in the prion protein by hydrogen peroxide. Arch Biochem Biophys 2004; 432: 188-95.

36. Lee $S$, and Eisenberg D. Seeded conversion of recombinant prion protein to a disulfide-bonded oligomer by a reduction-oxidation process. Nat Struct Biol 2003; 10: 725-30.

37. Shiraishi N, Inai $Y, B i ~ W$, et al. Fragmentation and dimerization of copper-loaded prion protein by copper-catalysed oxidation. Biochem J 2005; 387: 247-55. 